Sparkes, I, Frigerio, L, Tolley, N and Hawes

The plant endoplasmic reticulum: a cell-wide web.

Biochemical Journal, 2009, 423 (2). pp. 145-155.

10.1042/BJ20091113

This version is available: http://radar.brookes.ac.uk/radar/preview/e5005581-0415-c038-1048-0bce69b0a950/1/

Available on RADAR: November 2013

Copyright $(C$ and Moral Rights are retained by the author(s) and/ or other copyright owners. A copy can be downloaded for personal non-commercial research or study, without prior permission or charge. This item cannot be reproduced or quoted extensively from without first obtaining permission in writing from the copyright holder(s). The content must not be changed in any way or sold commercially in any format or medium without the formal permission of the copyright holders.

This document is the author's final version of the journal article. Some differences between the published version and this version may remain and you are advised to consult the published version if you wish to cite from it. 


\title{
The Plant Endoplasmic Reticulum: A Cell-Wide Web
}

\author{
Imogen A. Sparkes ${ }^{1}$, Lorenzo Frigerio ${ }^{2}$, Nicholas Tolley ${ }^{2}$ and Chris Hawes ${ }^{1 *}$ \\ ${ }^{1}$ School of Life Sciences, Oxford Brookes University, Oxford, OX3 0BP, UK \\ ${ }^{2}$ Department of Biological Sciences, University of Warwick, Coventry CV4 7AL, UK
}

*To whom correspondence should be addressed (email c.hawes@brookes.ac.uk)

Fax : +44 (0)1865 483955

Phone : $+44(0) 1865483266$

Keywords: Endoplasmic reticulum, Golgi apparatus, reticulons, exit sites, plastids, peroxisomes

All authors contributed equally to this review

Word count: 11332

Abbreviations used: ER, endoplasmic reticulum; RHD, reticulon homology domain; RTNLB, reticulon like; FRAP, fluorescence recovery after photobleaching; PAGFP, photoactivatable GFP; BFA, brefeldin A; ERES, ER exit sites; ARF1, ADP

ribosylation factor 1; PAC, precursor accumulating; TAG, triacylglycerols; PMP, peroxisome membrane proteins. 


\section{SUMMARY}

The endoplasmic reticulum (ER) in higher plants forms a pleomorphic web of membrane tubules and small cisternae that pervade the cytoplasm, but in particular form a polygonal network at the cortex of the cell which may be anchored to the plasma membrane. The network is associated with the actin cytoskeleton and demonstrates extensive mobility, which is most likely dependent on myosin motors. The ER is characterised by a number of domains which may be associated with specific functions such as protein storage, or with direct interaction with other organelles such as the Golgi apparatus, peroxisomes and plastids. Here we discuss the nature of the network, the role of shape forming molecules such as the recently described reticulon family of proteins and the function of some of the major domains within the ER network.

\section{INTRODUCTION}

The endoplasmic reticulum (ER) was first described by electron microscopists in the 1960s [1]. Subsequently, the development of vital stains, improved tissue preservation techniques and video imaging technology [2], culminating in the exploitation of fluorescent protein technology [3], has allowed the documentation of the extremely dynamic and pleomorphic nature of the ER (Fig.1, supp. movie 1, see Hepler et. al. and references therein [3, 4]).Traditionally the ER has been classed into two forms, rough and smooth, depending on the presence or absence of membrane bound ribosomes [5]. However, the highly dynamic nature of the organelle is exemplified by the rapid changes that can be made between cisternal and tubular forms in response to developmental [6,7], physiological [8] or environmental cues. It is these two morphological forms that are now more commonly used to describe the organelle, even though their importance was apparent from earlier work using selective membrane staining and thick section electron microscopy [9-11]. For instance, in developing Arabidopsis roots cisternal ER is more common in meristematic and elongating cells, whereas tubular forms predominate in the more vacuolate and mature elongated cells [6]. Positionally, the ER can be described in terms of two populations, the cortical network and cytoplasmic ER which may also extend across trans-vacuolar strands [8]. Both forms of ER exhibit motility, although cytoplasmic ER may also get caught in cytoplasmic streams and thus show much more rapid unidirectional movement.

The ER effectively compartmentalises the cytoplasm into two fractions, a reducing cytosol and an oxidising ER lumen, bounded by the ER membrane. The outer nuclear envelope can also be considered to be a distinct domain of the ER being connected to the tubular network and, in some algae such as the yellow-green xanthophyte Tribonema, can function as the ER, transporting cargo directly to the cis-Golgi [12]. The ER has numerous and diverse functions from the generic biosynthesis of phospholipids, the synthesis, glycosylation, folding and quality control of secretory proteins [13-15], the maintenance of the calcium homeostasis of the cell [16], through to the more specialised formation of storage material such as protein and oil bodies [17-19]. Clear links between these multiple biological functions and the unique morphology and dynamics of the ER, however, have not yet been established. 
In this review we will focus on recent data that have revealed the true dynamic nature of the ER network in plant cells and the functional significance of some of the more important ER domains.

\section{THE ER AS A DYNAMIC MEMBRANE NETWORK}

As previously mentioned, a typical ER network is composed of several structurally distinct domains; tubules, cisternae and the nuclear envelope. In any given static 'snapshot' of the cortical ER, the vast majority of tubules form a polygonal network underlying the plasma membrane and are interconnected by three-way junctions, with a small subset of 'open ended' tubules undergoing growth/retraction (Fig. 1, supp. movie 1). The continual extension/retraction of tubules appears to be random, although outgrowth has been observed to follow the track of Golgi bodies in tobacco epidermal cells [20]. Static nodules of ER within the dynamic network have been reported in onion bulb cells, and are also apparent in tobacco and Arabidopsis epidermal cells [21]. Recent micromanipulation studies in Arabidopsis leaf epidermal cells have indicated that these static 'islands' of ER appear to act as anchor points, presumably connected through to the plasma membrane, around which the ER remodels [22]. Drastic rearrangements of the entire network also appear to be random, apart from regions of 'fast-flowing' movement which coincide with cytoplasmic streaming. Therefore, based on these morphological observations, ER network remodelling requires factors that regulate tubule extension, network stabilisation, three-way junction and anchor point formation, and modulation of ER shape through tubulation versus cisternalisation (Fig. 2). Given the complexity of these factors and the highly dynamic nature of the ER network, efforts to model ER movement have been limited to date in any system, with static models of ER geometry [23-25] providing the foundation for future studies.

Unlike animal cells, the cortical ER network in higher plants overlies the actin cytoskeleton rather than microtubules [26-28]. Despite this fundamental difference, depolymerisation of the actin or microtubules in higher plants [21] and mammals respectively does not result in a concomitant destruction of the ER network, but does perturb tubule extension and remodelling [29]. While microtubule depolymerisation appears to have no effect on ER dynamics in mature, non-growing cells [20], it does affect the cortical network in elongating characean internodal cells [30]. ER in characean internodal cells can be split into two types; a fast cytoplasmic streaming region in the endoplasm, and the more 'sedate' cortical network above. Drug inhibition studies have shown that whilst the streaming ER is dependent on actin, cortical network remodelling is dependent on the microtubules during the early stages of cell elongation. It has also been reported that oryzalin has an effect on ER dynamics in tobacco leaf epidermal cells, Arabidopsis roots and BY-2 cells but the effects were specific to the drug rather than microtubule depolymerisation per se [31]. Furthermore, in mammals, long-term depolymerisation of microtubules (2 hours opposed to 15 minutes) and overexpression of full length and truncations of several microtubule-interacting proteins (CLIMP-63, tau, kinesin) results in ER network shrinkage [29] (and see review [27] and references therein). Therefore, the cytoskeleton plays an important role in tubule extension and, in mammals, network stabilisation. Interestingly, in vitro reconstitution studies on Xenopus ER microsomes have indicated that ER network formation can occur in the absence of microtubules 
and thus the formation of a polygonal network may be an intrinsic property of ER membrane [32].

\section{Myosins and ER movement}

It is well documented that organelle movement in higher plant cells is actin-dependent [26, 33-39] and thus it has been assumed that myosin motors are generating the motive forces. The role of myosins has received much attention of late, and the genetic dissection of the 17 Arabidopsis myosin genes has been carried out through overexpression of truncated variants lacking the myosin head domain [40-43]. RNAi down-regulation and T-DNA insertional mutagenesis have verified the role of some myosin isoforms in organelle movement [42-44]. The 17 myosins are split into two classes: VIII contains 4 members and XI contains 13. Class XI has been implicated in organelle movement [40-43]. Tracking algorithms can quantify the movement of discrete organelles such as Golgi bodies, peroxisomes and to some extent mitochondria. The movement characteristics of the ER network are more complicated, and algorithms to relatively easily monitor ER characteristics such as tubule growth, network remodelling, surface area versus volume are currently underway and still in their infancy [25]. Once these have been developed, a comprehensive study of any drastic or subtle effects of these myosins on ER remodelling can be undertaken. Localisation studies have indicated that of the 17 Arabidopsis myosins, class VIII myosin ATM1 is present in small puncta which were proposed to overlie the ER, although its effects on ER dynamics were not documented [45]. Biochemical cofractionation and immunocytochemistry studies have indicated that a $175 \mathrm{kDa}$ heavy chain myosin is associated with the ER in tobacco BY-2 cells and therefore may be responsible for network dynamics [46]. Overexpression of two myosin tail domains (XIK and XI2) in tobacco were reported to have no effect on ER structure, although studies on ER dynamics were not presented [42].

\section{Tubule formation, cisternae and anchoring}

While the cytoskeleton provides the tracks along which ER tubule extension occurs, the 'extended' membrane is presumably composed of either 'stretched' ER membrane growing and flexing in new directions, or of de novo synthesised ER membrane. Such growing tubules can fuse laterally with other tubules forming the new polygons. Thus, multiple homotypic membrane fusions can be generated along one ER tubule. In mammals several genes have been shown to have an essential role in homotypic membrane fusion (see [27] and references therein). To date there are no candidate plant proteins mediating such fusion events, other than potential ER SNAREs [47].

Factors regulating three-way junction and anchor point formation are unknown (Fig. 2). An intriguing possibility is that anchor points attach the ER to the plasma membrane thus 'anchoring' it in place in the cell as suggested from the video enhanced microscopy studies of onion epidermal cells [2]. There is, however, no evidence to suggest that anchor points necessarily correspond with the position of tripartite junctions. Thus, three-way junction formation could simply be a thermodynamically favourable configuration of stretched, interconnected membrane tubules.

The biological significance of ER shape in terms of tubulation versus cisternalisation is an interesting topic which is gaining renewed interest. A shift to cisternal over tubular ER was proposed to occur due to an increased secretory load in differentiating 
maize root cap cells [10] and during mobilisation of seed storage protein in germinating mung bean cotyledons [9]. Similar conclusions were drawn from several studies in mammals; Rajasekaran et. al. [48] showed that upon inducing secretion in rat pancreatic acinar carcinoma cells, the rough ER undergoes a structural change from tubular to cisternal form. However, this structural change was not concomitant with an overall increase in surface area, leading the authors to postulate that cisternal ER is more biosynthetically efficient. Additionally, overexpression of certain membrane proteins induces a shift to a more cisternal form of ER over tubular [49], as does a block in ER-Golgi trafficking through BFA treatment and expression of dominant negative mutants involved at the ER-Golgi interface [50]. Intriguingly, ER remodelling is drastically affected during oomycete infection of leaves and can be mimicked by mechanical stimuli $[51,52]$. In both cases ER cisternae form around the infection/wound site, and are hypothesised to reflect increased protein and/or lipid production for the delivery of defence-related compounds to the site of action [51]. However, it is unclear whether this is a direct or indirect effect of the remodelling of the underlying cytoskeleton. Internal/external scaffold proteins, or regulation of internal volume by ion pumps and water flow restriction [53] have been suggested to control ER tubulation. However, the latter two models may be difficult to reconcile with the dynamic nature and permeability of the ER membrane.

\section{Reticulons}

As mentioned previously, the shape of the tubular ER does not depend on its attachment to the cytoskeleton [32], indicating the requirement for factors present within the ER membrane itself. It has recently been found that a family of membrane proteins called reticulons are enriched in tubular ER and can lead to ER tubule formation in an in vitro assay [54]. Reticulons are ubiquitous in higher eukaryotes. They contain a signature reticulon homology domain (RHD) which comprises two large hydrophobic regions, possibly further subdivided into four membrane-spanning segments [55]. Each RHD transmembrane segment is longer than the typical transmembrane helices of ER-localised membrane proteins [56], and therefore is likely to be inserted into the ER membrane at an angle [57, 58]. This wedge-shaped conformation is postulated to confer curvature to the ER membrane [59, 60] (Fig. 2). The topology of plant reticulons has not yet been determined experimentally. Bioinformatic topology prediction for the Arabidopsis reticulon gene family using TOPCONS indicates that all members have a predicted ' $\mathrm{W}$ ' topology, with $\mathrm{N}$ and $\mathrm{C}$ termini, plus the short loop between the large hydrophobic regions, exposed to the cytosol [61]. The same topology was described experimentally for mammalian Rtn4c [54]. A direct link between reticulon topology, transmembrane domain length and curvature has however not been established yet.

In the first systematic classification of reticulons [55], plant reticulon genes were denominated RTNLB (reticulon-like gene in plants, i.e. non-metazoan group $\underline{B}$ ). Reticulon genes are very abundant in higher plants [55]. While only a single reticulon-like sequence was found in a search of the genome of the green alga Chlamydomonas reinhardtii, the moss Physcomitrella patens has at least 9 isoforms, and at least 5 reticulon-like proteins are encoded by the spikemoss Selaginella moellendorffii genome (Fig. 3). The Arabidopsis genome contains 21 isoforms (reported in [62]). Only 4 reticulon genes have been described in the human genome so far, but alternative splicing may account for more numerous protein products [55]. The explosion of plant RTN gene diversity is very likely to reflect the increasing 
complexity and multifunctional role of the ER during higher plant evolution. It is tempting to speculate that different reticulons may underpin the variety of plant ER subdomains [63] and specialized ER functions such as the biosynthesis of oil bodies [64]. While the RHD are highly conserved and the C-termini of reticulons are in general rather short, the N-terminal regions of reticulons are highly variable both in length and in sequence. This suggests that the $\mathrm{N}$-terminus may be the key region for the intrinsic reticulon biological activity and protein-protein interactions. The Arabidopsis sequences of RTNLB17 to 21 stand out for a particularly long Nterminus that likely carries enzymatic activity [62]. Indeed, RTNLB19 was first identified for its activity as a 3- $\beta$-hydroxysteroid dehydrogenase/C-4 decarboxylase [65]. RTNLB20 is also annotated as a sterol dehydrogenase [66]. The Arabidopsis genome, however, encodes several sterol dehydrogenase isoforms that do not contain a RHD [65]. This, together with the fact that the long N-terminal regions of RTNLB17, 18 and 21 share similarity with a protein of so far unknown biological function, suggests that, beside its intrinsic structural role, the reticulon homology domain may have been employed as an ER membrane-tethering domain. As enzymelinked reticulons also exist in P. patens and S. moellendorffii (Fig. 3), it is possible that the differentiation between reticulon-like tethers and 'structural' reticulons occurred early during plant evolution.

Plant reticulons have so far attracted limited attention, with only three functional works published in the literature [62, 67, 68]. Three reticulons (RTNLB1, 2 and 4) were found to interact with a pilin protein of Agrobacterium tumefaciens in a yeast two-hybrid screen [67]. Downregulation of RTNLB1 by antisense resulted in lower rates of Agrobacterium-mediated transformation. GFP fusions to the coding sequences of these reticulons appeared to localise in structures reminiscent of the cortical ER in Arabidopsis roots [67]. It will be interesting to understand how these ER membrane proteins interact in vivo with the pilus proteins of Agrobacterium.

More recently, in an independent study, RTNLB2 and RTNLB4 were again fused to GFP and confirmed that these proteins localise to the ER, but also in punctate structures, in transgenic Arabidopsis or in transiently transfected protoplasts. No functional roles were established [62]. ER residence of RTNLB1 and RTNLB3 was also confirmed by recent proteome localisation data [69].

Our laboratories cloned one of the smallest reticulon isoforms, RTNLB13, which comprises an intact RHD flanked by very short $\mathrm{N}$ - and $\mathrm{C}$-terminal regions. Upon overexpression of untagged RTNLB13 in tobacco epidermal cells, the cortical ER lost its normal reticular shape and became strikingly fragmented. However, when RTNLB13-YFP was coexpressed with the luminal marker GFP-HDEL, it was apparent that ER tubules remained intact (Fig. 4). The observed fragmentation results from a remodelling of the luminal space. FRAP analysis confirmed that overexpression of RTNLB13 results in the severely restricted diffusion of luminal ER proteins [68]. Preliminary analysis of anterograde transport by monitoring the secretory kinetics of a reporter protein under RTNLB13 overexpression indicated that, despite this severe morphological phenotype at the level of the ER, anterograde protein transport is unaffected [68]. This seems to indicate that a fully connected tubular ER network may not be necessary for a functional secretory pathway. Intriguingly, overexpression of RTNLB13 results in nodes of seemingly unrestricted ER lumen even though RTNLB13 surrounds these areas (Fig. 4). Based on the earlier discussion of ER dynamics, it is possible that lack of restriction is due to steric 
hindrance from large protein complexes / scaffolds at immotile anchor points and /or potential interactions with factors required for ER network stability, perhaps with actin (Fig. 2).

16 out of the 21 Arabidopsis reticulons contain the canonic dilysine ER membrane retrieval motif KKXX [70, 71]. The addition of fluorescent proteins to the C-terminus of RTNLB2 and 4 however did not prevent the proteins form localising to the ER [62]. Similarly, C-terminal tagging of RTNLB13 with YFP did not affect ER localisation and stability [68]. It is possible that ER residence is afforded by the transmembrane topology of RTN and, more importantly, by their ability to interact with other ER-resident proteins or to homo-oligomerise [72]. The di-lysine motif could then have persisted either as an evolutionary relic or a safety valve mechanism.

Some of the interactions that guarantee ER residence are likely to be homotypic, as described for mammalian reticulons [72]. Indeed, RTNLB1-3 were found to interact with each other, as well as with AtRabE1a, in a yeast two-hybrid assay [67]. No other interactions have so far been described for plant reticulons.

\section{Dynamics of the ER surface}

ER dynamics can be split into two types; network remodelling as described above and movement of the ER membrane surface itself. Recently, Runions et. al. [49], using a photoactivatable GFP (PAGFP) fusion to the trans-membrane domain of calnexin (an ER resident chaperone), demonstrated that upon photoactivation the fluorescent pool of protein displayed varying velocities and migrated in a radial or vectorial manner. Upon depolymerisation of the actin cytoskeleton, only radial diffusive movement of the photoactivated pool was observed, indicating an actin-dependent vectorial movement. Such studies demonstrated that, in tobacco leaf epidermal cells, if activation of the PAGFP construct on the ER membrane is continuous, the whole of the ER network can become fluorescent in 11 minutes, indicating that the whole pool of ER-targeted protein must pass through the activation spot in that time (J. Runions, pers. comm.). Such data indicate the ER may present a mobile surface permitting movement of proteins within the cell. Certainly the ER has been implicated in the transport of viral movement proteins from the sites of synthesis in TMV infected tobacco cells to the plasmodesmata during the infection process [73, 74] and more recently in the movement of viral RNA granules [74, 75]. Further studies are required to quantify the types and the physiological significance of membrane surface movement.

\section{FUNCTIONAL DOMAINS OF THE ENDOPLASMIC RETICULUM}

It has been suggested that there are numerous functional domains within the ER network of a plant cell, ranging from areas which accumulate specific products to connections with individual organelles [63]. For instance it has been hypothesised that the junction between the outer nuclear envelope and the endoplasmic reticulum forms a gated domain which controls the exchange of protein between the two organelles [63]. However, photobleaching experiments using GFP tagged constructs of ER resident proteins have shown that there can be free diffusion of protein between the lumen of the nuclear envelope and ER [20], although some degree of control here could be expected as these connections would be the site of entry of membrane bound 
proteins specific to the inner and outer nuclear envelopes [76]. Another major domain would be at the plasma membrane where the desmotubules of plasmodesmata are most likely formed from compression of cortical ER passing between neighbouring cells [77]. This extensive topic is however, outside the scope of this review.

\section{ER exit sites}

Perhaps the most dynamic and controversial domain of the endoplasmic reticulum is that which represents sites of export to the Golgi apparatus, the so called ER exit sites (ERES). This critical junction in the secretory pathway mediates the transport of both soluble and membrane cargo (proteins and lipids) and somehow involves the COPII coat protein machinery [78]. Transport between the two organelles can be bidirectional and it is thought that retrograde transport from the Golgi to the ER is mediated by COPI vesicles, as blockage of the COPI machinery either by brefeldin A (BFA) [79] or by expression of non-functional ADP ribosylation factor 1 (ARF1) results in the redistribution of Golgi membrane markers into the ER [80]. All the molecular components of ERES identified in yeast and mammalian cells exist in plants $[78,81]$ and most of the components, with the exception of the exit site scaffold protein Sec 16 [82] have been co-located to the Golgi using fluorescent protein constructs.

In leaves, live cell imaging of epidermal cells expressing a range of exit site markers such as the small GTPase Sar1p [50], COPII coat components Sec23p/Sec24p, Sec 13 [80, 83], ER and cis-Golgi SNARES [84] in combination with Golgi membrane markers [26] resulted in the development of the 'motile export site' hypothesis. This proposes that Golgi bodies and the ER exit site exist as a tight unit embedded into the ER membrane and are motile over the ER membrane [49, 50, 78]. Such a concept has been challenged in BY2 cells where Yang et. al. [85] suggested there was only transient association of Golgi stacks with ERES. However, more recently it has been confirmed that in Arabidopsis leaves, tobacco leaves and BY2 cells, COPII exit site proteins Sec24 and Sec13 maintain a constant association with Golgi stacks [83]. Thus, unless new Golgi stacks are being formed, exit sites and Golgi bodies are never found separate from each other. It has however been shown that the ER has the capacity to form new exit sites, and thus new Golgi, in response to the expression of membrane cargo such as the ERD2 protein, but not in response to over-expression of soluble secretory cargo such as secreted GFP [86]. Also the ER has the capacity to produce new Golgi stacks after the dissolution of the Golgi with Brefeldin A [79]. A study on tobacco BY2 cells showed that the first reformation event was the appearance at the ER surface of buds and clusters of vesicles which appeared to fuse together to form mini-stacks that subsequently differentiated into large Golgi stacks prior to fission into two stacks [87]. To date there is no evidence that this process requires the formation of free COPII vesicles at the ERES.

The exact physical nature of ER exit sites is a matter of controversy. In leaves, hypocotyls and suspension culture cells (i.e. vacuolate cells) it is clear that Golgi bodies are intimately associated with the ER [26, 78, 88]. However the structure of the ER-Golgi interface is still a matter of speculation. We have proposed that due to the closeness of the two organelles, cargo transfer could easily be mediated by direct membrane connections or tubules [89]. This would require the COPII scaffold to form in order to initiate membrane curvature and maybe concentrate putative cargo receptors, but would not require the formation of independent COPII vesicles. Thus, 
the Golgi itself could be considered to be a specialised domain of the ER with ERES initiating the biogenesis of a new Golgi stack depending on the physiological requirements of the cell. Direct connections between the plant Golgi and the ER have long been reported in the ultrastructural literature using conventional fixation and selective staining techniques [20,90-93]. In contrast, there have been no reports of COPII vesicles between the ER and Golgi in the majority of plant tissues studied by live cell imaging of ER and Golgi. In rapidly frozen freeze-substituted root and suspension culture material, however, tomographic analysis reveals vesicles which were assumed to be COPII $[94,95]$. These data were used to support the 'stop-andgo' hypothesis of Golgi function, whereby rapidly moving free Golgi are captured by tethering proteins such as P115 (see below) at the ERES, where cargo exchange takes place via COPII vesicles. When replete, Golgi bodies would be released back into the cytosol. However, until the necessary live cell imaging experiments can be successfully carried out on such cytoplasmically dense cells, there will be no firm evidence for one population of Golgi stacks that exist free of the ER and another population that is permanently attached to ER exit sites, but can occasionally break free from their tethers [89]. However, it is clear that in meristems Golgi movement appears restricted compared with that in more vacuolate cells and as such it is possible that there may be populations of Golgi stacks with different ER associations [78].

The functional connection between the ER and Golgi body is mirrored by the close association of the two compartments; live cell imaging has indicated that Golgi body movement appears to mirror the underlying ER (supp. movie 2), and on occasion ER tubule formation appears to follow the path of Golgi bodies [20, 26, 49]. Therefore, based on these observations, the question as to whether the movement of these compartments are (in) dependent of one another was posed [89]. Recently, using laser trapping technology we have shown that it is possible to capture and manipulate individual Golgi bodies in Arabidopsis leaf epidermal cells co-expressing fluorescent ER and Golgi markers [22]. If the actin cytoskeleton was depolymerised to inhibit Golgi movement, Golgi bodies associated with the cortical ER could be captured in the focussed laser beam and any lateral movement of the beam resulted not only in lateral displacement of the Golgi stack but also in the extension or growth of the associated ER tubule (Fig. 5, supp. movie 3). Thus, Golgi bodies do appear to have an attachment to the ER. On occasions when Golgi bodies could be pulled free from ER tubules it was possible to recapture the ER simply by docking a Golgi body onto the tip of the tubule, which resulted in attachment being re-established. This supports the contention that there must be a system of tethering factors or peripheral matrix proteins that can freely attach to the ER maintaining the cohesiveness of the export site/Golgi complex [94]. These results do not formally prove that in an unperturbed system Golgi body movement induces ER remodelling directly. Therefore, the question remains as to whether Golgi body movement and ER remodelling are interdependent processes which utilise the same set of molecular motors/tethering factors, or whether actin polymerisation directly affects ER tubule growth through tethering factors (Fig. 2).

Although there is an extensive literature on ER-Golgi tethering factors in mammalian and yeast cells (see $[96,97]$ ) only recently have peripheral membrane proteins been identified in plant Golgi which may have a tethering role $[98,99]$. Some of these, the homologues of P115, CASP and Golgin 84 appear to be located towards the cis-face of the Golgi and could be candidates for ER tethering factors [94, 98]. Sinka et. al.. 
[100] have recently proposed a model for the Golgi whereby the organelle is surrounded by a mass of tentacular molecules of tethering protein that, via Rab binding sites, capture Rab containing membranes such as ER to Golgi carriers. Some plant trans-Golgi associated proteins have also been shown to bind small ATPases such as ARL1 [101-103] and AtRabH1 ${ }^{\mathrm{b} / \mathrm{c}}$ [102]. As yet, Rab binding has not been reported on cis-Golgi proteins but such a model could explain the ability of individual laser-trapped Golgi to re-capture ER membranes.

\section{PAC vesicles and ER-to-vacuole transport}

Several proteins can be targeted to the vacuole directly from the ER, in a route that does not involve the Golgi apparatus. Hara-Nishimura [104] reported that pumpkin storage protein precursors exit the ER in large precursor- accumulating (PAC) vesicles which eventually fuse with protein storage vacuoles. The PAC vesicles seem to acquire proteins carrying Golgi-modified $\mathrm{N}$-glycans, which are seen by EM at the periphery of the ER-derived protein core [104]. In addition to storage proteins, a class of cysteine proteases which carry the ER retention signal H/KDEL, have also been observed to travel to the vacuole, where the ER retention signal is removed [105]. A small proportion of some recombinant proteins bearing H/KDEL have also been shown to reach the vacuole, in a route that may [106] or may not [107] require transport through the Golgi apparatus. The molecular details of these ER-to-vacuole transport routes are at present unclear.

\section{The ER as a storage compartment: Oil bodies, grass storage proteins, fusiform bodies.}

Whether or not they can be classified as specific domains, the ER in many tissue types has the capacity to store material in so called "ER bodies" [19]. Such material can either remain in the ER or be exported from the ER and exist as discrete organelles such as oil bodies or protein bodies $[19,63]$.

Oil bodies are essential storage organelles in seeds and are formed from the endoplasmic reticulum by insertion of triacylglycerols (TAGs) within the lipid bilayer of the ER (see [108] for review). TAGs are synthesised by diacylglyceride transferases (DGAT) which are located to distinct sub-domains of the ER [109]. Being hydrophobic, TAGs accumulate between the lipid bilayer and form a bud that enlarges into an oil body, which can eventually break free from the ER. The lipid monolayer of the oil body is characterised by small proteins of the oleosin family which cover the surface of the oil bodies. These proteins are synthesised on the ER membrane and are transported on the ER to sites of synthesis of oil bodies [110]. This again demonstrates the capacity of the ER surface to act as a dynamic surface for transport of macromolecules (see above).

In dicotyledonous plants, most of the protein that is destined for storage in specialised vacuoles during seed maturation is passed through the Golgi apparatus and deposited in a storage vacuole $[111,112]$. However, in many grasses and cereals storage proteins such as the prolamins are sequestered in the ER as an insoluble matrix and form distinct protein bodies that may remain in the ER or be delivered directly to the vacuole for storage $[15,17,19,113]$. 
Perhaps one of the most striking examples of "ER bodies" are the fusiform bodies commonly found in the lumen of the ER of Arabidopsis and highlighted by many GFP fusions $[18,114,115]$. These can be large, 1 micron in diameter and up to 10 microns long and predominantly contain a $\beta$-glucosidase (PYK10) with the Cterminal ER retrieval KDEL motif. Similar bodies containing an inducible $\beta-$ glucosidase (BGL1) have been identified in wounded cotyledons and rosette leaves. Remarkably, these fusiform bodies move at considerable speed in the cytosol and as it is assumed that the ER has no luminal cytoskeleton, the motive force must come from movement of the whole of the ER, thus reflecting the motile nature of this organelle, as revealed by the photoactivation experiments [49].

\section{Peroxisome biogenesis and the role of the ER}

Until recently, the potential role of the ER in peroxisome biogenesis has been hotly debated. The cortical ER is far reaching throughout the cell, and observations indicating an intimate association between the ER and other classes of organelle can be frequently found. This is compounded by the variable morphology of peroxisomes, which in some cases are spherical but can even have long tail-like protrusions called peroxules [37, 116], which apparently co-align with the ER [117]. Such observations, and the occasional apparent direct membrane continuities between peroxisomes and the ER seemed to indicate that peroxisomes arose from the ER [118]. However, the development of molecular and genetic tools proved that peroxisome matrix proteins were synthesised on free polyribosomes and inserted directly into peroxisomes via interaction with cytosolic receptors (PEX5 and PEX7). The 'multiplication-bydivision' model whereby peroxisomes arise from growth and division of pre-existing peroxisomes was thus proposed [119]. However, this model could not reconcile how peroxisomes were able to be synthesised de novo in certain yeast and mammalian cell line mutants, and how peroxisome membrane proteins (PMPs) and lipids could be synthesised and transported to the organelle.

Several targeting studies and chemical (BFA) perturbation at the ER-Golgi interface have indicated that certain plant PMPs (APX, PEX10, PEX16) are located to the ER [120-126]. However, transient expression studies in tobacco leaf epidermal cells indicated that both PEX2 and PEX10 do not localise to the ER upon BFA treatment or through genetic perturbation (Sar1-GTP locked mutant) at the ER-Golgi interface [127]. Studies of Tomato Bushy Stunt Virus (TBSV) replication protein, p33, have shown that it targets to the peroxisomes and traffics to the ER in vesicular carriers containing PMPs, but it is unclear whether this retrograde pathway occurs in uninfected cells [128]. Similar studies of PMPs in yeast and mammalian cell cultures have been performed, and are detailed in several reviews [129, 130]. The development of new fluorescent protein tools allowing the visualisation of pools of protein through photoactivation, have shown that Pex16p, a PMP in mammals, is present in the ER and subsequently traffics to the peroxisomes [131].

The current model for peroxisome biogenesis therefore appears to be an interplay between the autonomous 'multiplication-by-division' and the ER vesiculation model, whereby peroxisome precursors containing early PMPs bud from the ER into which additional matrix and late PMPs are post-translationally inserted to allow for growth and division. 


\section{ER-plastid interactions}

For many years there have been regular reports of connections between ER and plastid envelopes (see [132] and [63] for reviews) which have mainly been from ultrastructural studies [133]. This has led to much speculation as to the function of such connections and whether they also facilitate direct transfer of macromolecules between the two organelles.

It is well established that chloroplast development requires lipid precursors, such as diacylglycerols, that are synthesised in the ER membrane $[132,134]$. Therefore there has been much speculation on the possible routes of transfer of lipid precursors from the ER to the plastid membrane, including protein-mediated transfer, vesicle trafficking or direct transfer via contact sites between the two organelles [132]. The validity of these contact sites has been tested in protoplasts expressing GFP targeted to the lumen of the ER. On rupturing protoplasts, ER fragments remained attached to chloroplasts [134] and optical trapping and displacement of such chloroplasts resulted in stretching out of the ER fragments [135]. This does not however preclude the possibility that the ER in such a disrupted system is "sticky" and experiments need to be performed in vivo to confirm these results. Recently an Arabidopsis gene (TGD4) has been described which encodes an ER membrane protein which is proposed to be a component of the machinery mediating lipid transfer to the chloroplast membrane as a mutant prevents the availability of ER diacylglycerol for chloroplast galactoglycerolipid synthesis [134]. The authors proposed one model where TGD4 could be active in mediating lipid transfer at ER chloroplast contact sites. However, it has also been reported that there may be a trafficking pathway from the ER to plastids via the Golgi apparatus. Several chloroplasts proteins including an carbonic anhydrase [136] and a nucleotide pyrophosphatase/phosphodiesterase [137] have been shown to be N-glycosylated and their transport BFA sensitive indicating transport through the Golgi. If it is assumed that the transport vector from the Golgi to the chloroplast is membrane bounded then this could also be a pathway for the trafficking of plastid lipids or lipid precursors.

Whilst it is not impossible that such ER plastid membrane contact sites are involved in lipid transfer between the organelles it must be appreciated that in many cells there is limited free cytosolic space. This may be restricted by large central vacuoles or even by the sheer number of chloroplasts themselves. Therefore, in the context of the presence of a highly mobile ER phase within the cell it is hardly surprising that it frequently makes and breaks contact with the surface of other organelles.

Another possible function of the cortical ER network is a role in graviperception of statocytes. A number of years ago it was suggested that graviperception may be sense by the sedimentation of amyloplasts (statoliths) onto cortical ER in root cap statocytes which would generate a signal to the root growth zone [138]. This model however was subsequently dismissed [139], but has recently been revisited [140]. In Arabidopsis root cells it was shown that sedimenting statoliths can cause deformation of cortical ER, as they are induced to sediment by reorientation of the root. It was proposed that this interaction is a mode of mechanosensing that could induce the gravity perceiving response. 


\section{OUTSTANDING QUESTIONS}

Although the ER is one of the major organelles in the cell occupying a major portion of the cytosol, and much is known about its functions in terms of protein synthesis, folding, glycosylation and quality control, there are still many questions to be answered regarding its structure and relationships to other organelles. For instance, why does the ER maintain such an energetically unfavourable shape in being tubular with some cisternae, while alterations to its shape do not seem to severely affect anterograde secretory traffic? Is there a function for the movement of the ER network in terms of moving proteins and even other organelles around the cytoplasm? Is there direct exchange of lipids and protein between the ER and other organelles such as mitochondria and plastids and - most intriguingly - what proteins are involved in anchoring the cortical ER network to the plasma membrane? Is there direct molecular exchange with the plasma membrane and is the cortical microtubule network interacting in any way with the ER? Such questions will undoubtedly be addressed in the near future.

\section{Acknowledgments}

We thank Stefano Gattolin and Eleanor Pinnock for help with the phylogenetic analysis of plant reticulons. Work in the $\mathrm{CH}$ and LF laboratories has been funded by the Leverhulme Trust, BBSRC and EU PharmaPlanta consortium. 


\section{References}

1 Porter, K. R. and Machado, R. D. (1960) Studies on the endoplasmic reticulum. IV. Its form and distribution during mitosis in cells of onion root tip. J. Biophys. Biochem. Cy. 7, 167-180

2 Lichtscheidl, I. K. and Url, W. G. (1990) Organisation and dynamics of cortical endoplasmic reticulum in inner epidermal cells of onion bulb scales. Protoplasma. 157, 203-215

3 Boevink, P., Santa Cruz, S., Hawes, C., Harris, N. and Oparka, K. J. (1996) Virus-mediated delivery of the green fluorescent protein to the endoplasmic reticulum of plant cells. Plant J. 10, 935-941

4 Hepler, P. K., Palevitz, B. A., Lancelle, S. A. and McCauley, M. (1990) Cortical endoplasmic reticulum in plants. J. Cell Sci. 96, 335-373

5 Gunning, B. E. and Steer, M. W. (1969) Plant cell biology structure and function. Jones and Bartlett publishers Sudbury, USA

6 Ridge, R. W., Uozumi, Y., Plazinski, J., Hurley, U. A. and Williamson, R. E. (1999) Developmental transitions and dynamics of the cortical ER of Arabidopsis cells seen with green fluorescent protein. Plant Cell Physiol. 40, 1253-1261

7 Gupton, S. L., Collings, D. A. and Allen, N. S. (2006) Endoplasmic reticulum targeted GFP reveals ER organization in tobacco NT-1 cells drug in cell division. Plant Physiol. Bioch. 44, 95-105

8 Quader, H., Hofmann, A. and Schnepf, E. (1989) Reorganisation of the endoplasmic reticulum in epidermal cells of onion bulb scales after cold stress: Involvement of cytoskeletal elements. Planta. 177, 273-280

9 Harris, N. and Chrispeels, M. J. (1980) The endoplasmic reticulum of mungbean cotyledons:quantitative morphology of cisternal and tubular ER during seedling growth. Planta. 148, 293-303

10 Stephenson, J. L. M. and Hawes, C. R. (1986) Stereology and stereometry of endoplasmic reticulum during differentiation in the Maize root cap. Protoplasma. 131, $32-46$

11 Hawes, C. R., Juniper, B. E. and Horn, J. C. (1981) Low and high voltage electron microscopy of mitosis and cytokinesis in maize. Planta. 152, 397-407

12 Massalski, A. and Leedale, G. F. (1969) Cytology and ultrastructure of the Xanthophyceae. I. Comparative morphology of the zoospores of Bumilleria sicula Borzi and Tribonema vulgare Pascher. Brit. Phycol. J 4, 159-180

13 Pattison, R. J. and Amtmann, A. (2009) N-glycan production in the endoplasmic reticulum of plants. Trends Plant Sci. 14, 92-99

14 Vitale, A. and Denecke, J. (1999) The endoplasmic reticulum - gateway of the secretory pathway. Plant Cell. 11, 615-628

15 Vitale, A. and Boston, R. S. (2008) Endoplasmic reticulum quality control and the unfolded protein response: insights from plants. Traffic. 9, 1581-1588

16 Hong, B., Ichida, A., Wang, Y., Gens, J. S., Pickard, B. G. and Harper, J. F. (1999) Identification of a calmodulin-regulated $\mathrm{Ca}^{2+}$-ATPase in the endoplasmic reticulum. Plant Physiol. 119, 1165-1175

17 Vitale, A. and Ceriotti, A. (2004) Protein quality control mechanisms and protein storage in the endoplasmic reticulum. A conflict of interests? Plant Physiol. 136, 3420-3426

18 Hara-Nishimura, I., Matsushima, R., Shimada, T. and Nishimura, M. (2004) Diversity and formation of endoplasmic reticulum-derived compartments in plants. Are these compartments specific to plant cells? Plant Physiol. 136, 3435-3439 
19 Herman, E. M. (2008) Endoplasmic reticulum bodies: solving the insoluble. Curr. Opin. Plant Biol. 11, 672-679

20 Brandizzi, F., Snapp, E. L., Roberts, A. G., Lippincott-Schwartz, J. and Hawes, C. (2002) Membrane protein transport between the endoplasmic reticulum and the Golgi in tobacco leaves is energy dependent but cytoskeleton independent: evidence from selective photobleaching. Plant Cell. 14, 1293-1309

21 Knebel, W., Quader, H. and Schnepf, E. (1990) Mobile and immobile endoplasmic reticulum in onion bulb epidermis cells : short- and long-term observations with a confocal laser scanning microscope. Eur. J. Cell Biol. 52, 328-340

22 Sparkes, I. A., Ketelaar, T., De Ruijter, N. C. A. and Hawes, C. (2009) Grab a Golgi: Laser trapping of Golgi bodies reveals in vivo interactions with the endoplasmic reticulum. Traffic. 10, 567-571

23 Sbalzarini, I. F., Mezzacasa, A., Helenius, A. and Koumoutsakos, P. (2005) Effects of organelle shape on fluorescence recovery after photobleaching. Biophysical J. 89, 1482-1492

24 Radochova, B., Janacek, J., Schwarzerova, K., Demjenova, E., Tomori, Z., Karen, P. and Kubinova, L. (2005) Analysis of endoplasmic reticulum of tobacco cells using confocal microscopy. Image Anal. Stereol. 24, 181-185

25 Bouchekhima, A. N., Frigerio, L. and Kirkilionis, M. (2009) Geometric quantification of the plant endoplasmic reticulum. J. Microsc. 234, 158-172

26 Boevink, P., Oparka, K., Santa Cruz, S., Martin, B., Betteridge, A. and Hawes, C. (1998) Stacks on tracks: the plant Golgi apparatus traffics on an actin/ER network. Plant J. 15, 441-447

27 Vedrenne, C. and Hauri, H. P. (2006) Morphogenesis of the endoplasmic reticulum: beyond active membrane expansion. Traffic. 7, 639-646

28 Reuzeau, C., McNally, J. G. and Pickard, B. G. (1997) The endomembrane sheath : a key structure for understanding the plant cell? Protoplasma. 200, 1-9

29 Terasaki, M., Chen, L. B. and Fujiwara, K. (1986) Microtubules and the endoplasmic reticulum are highly interdependent structures. J. Cell Biol. 103, 15571568

30 Foissner, I., Menzel, D. and Wasteneys, G. O. (2009) Microtubule-dependent motility and orientation of the cortical endoplasmic reticulum in elongating Characean internodal cells. Cell Motil. Cytoskel. 66, 142-155

31 Langhans, M., Niemes, S., Pimpl, P. and Robinson, D. G. (2009) Oryzalin bodies:in addition to its anti-microtubule properties, the dinitroaniline herbicide oryzalin causes nodulation of the endoplasmic reticulum. Protoplasma. DOI 10.1007/s00709-009-0059-2

32 Dreier, L. and Rapoport, T. A. (2000) In vitro formation of the endoplasmic reticulum occurs independently of microtubules by a controlled fusion reaction. J. Cell Biol. 148, 883-898

33 Liebe, S. and Menzel, D. (1995) Actomyosin-based motility of endoplasmic reticulum and chloroplasts in Vallisneria mesophyll cells. Biol. Cell. 85, 207-222

34 Nebenfuhr, A., Gallagher, L. A., Dunahay, T. G., Frohlick, J. A., Mazurkiewicz, A. M., Meehl, J. B. and Staehelin, L. A. (1999) Stop-and-go movements of plant Golgi stacks are mediated by the acto-myosin system. Plant Physiol. 121, 1127-1141

35 Van Gestel, K., Kohler, R. H. and Verbelen, J. P. (2002) Plant mitochondria move on F-actin, but their positioning in the cortical cytoplasm depends on both Factin and microtubules. J. Exp. Bot. 53, 659-667 
36 Mathur, J., Mathur, N. and Hulskamp, M. (2002) Simultaneous visualisation of peroxisomes and cytoskeletal elements reveals actin and not microtubule-based peroxisome motility in plants. Plant Physiol. 128, 1031-1045

37 Mano, S., Nakamori, C., Hayashi, M., Kato, A., Kondo, M. and Nishimura, M. (2002) Distribution and characterization of peroxisomes in arabidopsis by visualization with GFP: Dynamic morphology and actin- dependent movement. Plant Cell Physiol. 43, 331-341

38 Collings, D. A., Harper, J. D. I. and Vaughn, K. C. (2003) The association of peroxisomes with the developing cell plate in dividing onion root cells depends on actin microfilaments and myosin. Planta. 218, 204-216

39 Jedd, G. and Chua, N. H. (2002) Visualization of peroxisomes in living plant cells reveals acto-myosin-dependent cytoplasmic streaming and peroxisome budding. Plant Cell Physiol. 43, 384-392

40 Sparkes, I. A., Teanby, N. A. and Hawes, C. (2008) Truncated myosin XI tail fusions inhibit peroxisome, Golgi, and mitochondrial movement in tobacco leaf epidermal cells: a genetic tool for the next generation. J. Exp. Bot. 59, 2499-2512

41 Avisar, D., Abu-Abied, M., Belausov, E., Sadot, E., Hawes, C. and Sparkes, I. A. (2009) A comparative study of the involvement of 17 Arabidopsis myosin family members on the motility of Golgi and other organelles. Plant Physiol. 150, 700-709

42 Avisar, D., Prokhnevsky, A. I., Makarova, K. S., Koonin, E. V. and Dolja, V. V. (2008) Myosin XI-K is required for rapid trafficking of Golgi stacks, peroxisomes and mitochondria in leaf cells of Nicotiana benthamiana. Plant Physiol. 146, 10981108

43 Peremyslov, V. V., Prokhnevsky, A. I., Avisar, D. and Dolja, V. V. (2008) Two class XI myosins function in organelle trafficking and root hair development in Arabidopsis thaliana. Plant Physiol. 146, 1109-1116

44 Prokhnevsky, A. I., Peremyslov, V. V. and Dolja, V. V. (2008) Overlapping functions of the four class XI myosins in Arabidopsis growth, root hair elongation and organelle motility. Proc. Natl. Acad. Sci. U.S.A. 105, 19744-19749

45 Golomb, L., Abu-Abied, M., Belausov, E. and Sadot, E. (2008) Different subcellular localizations and functions of Arabidopsis myosin VIII. BMC Plant Biol. $\mathbf{8}, 3$

46 Yokota, E., Ueda, S., Tamura, K., Orii, H., Uchi, S., Sonobe, S., HaraNishimura, I. and Shimmen, T. (2008) An isoform of myosin XI responsible for the translocation of endoplasmic reticulum in tobacco cultured BY-2 cells. J. Exp. Bot. 60, 197-212

47 Uemura, T., Ueda, T., Ohniwa, R. L., Nakano, A., Takeyasu, K. and Sato, M. H. (2004) Systematic analysis of SNARE molecules in Arabidopsis: dissection of the post-Golgi network in plant cells. Cell Struct. Funct. 29, 49-65

48 Rajasekaran, A. K., Morimoto, T., Hanzel, D. K., Rodriguez-Boulan, E. and Kreibich, G. (1993) Structural reorganization of the rough endoplasmic reticulum without size expansion accounts for dexamethasone-induced secretory activity in AR42J cells. J. Cell Sci. 105 ( Pt 2), 333-345

49 Runions, J., Brach, T., Kuhner, S. and Hawes, C. (2006) Photoactivation of GFP reveals protein dynamics within the endoplasmic reticulum membrane. J. Exp. Bot. 57, 43-50

50 DaSilva, L. L., Snapp, E. L., Denecke, J., Lippincott-Schwartz, J., Hawes, C. and Brandizzi, F. (2004) Endoplasmic reticulum export sites and Golgi bodies behave as single mobile secretory units in plant cells. Plant Cell. 16, 1753-1771 
51 Takemoto, D., Jones, D. A. and Hardham, A. R. (2003) GFP-tagging of cell components reveals the dynamics of subcellular re-organization in response to infection of Arabidopsis by oomycete pathogens. Plant J. 33, 775-792

52 Hardham, A. R., Takemoto, D. and White, R. G. (2008) Rapid and dynamic subcellular reorganization following mechanical stimulation of Arabidopsis epidermal cells mimics responses to fungal and oomycete attack. BMC Plant Biol. 8, 63

53 Voeltz, G. K., Rolls, M. M. and Rapoport, T. A. (2002) Structural organization of the endoplasmic reticulum. EMBO Rep. 3, 944-950

54 Voeltz, G. K., Prinz, W. A., Shibata, Y., Rist, J. M. and Rapoport, T. A. (2006) A class of membrane proteins shaping the tubular endoplasmic reticulum. Cell. 124, 573-586

55 Oertle, T., Klinger, M., Stuermer, C. A. O. and Schwab, M. E. (2003) A reticular rhapsody: phylogenic evolution and nomenclature of the RTN/Nogo gene family. FASEB J. 17, 1238-1247

56 Brandizzi, F., Frangne, N., Marc-Martin, S., Hawes, C., Neuhaus, J. M. and Paris, N. (2002) The destination for single-pass membrane proteins is influenced markedly by the length of the hydrophobic domain. Plant Cell. 14, 1077-1092.

57 Shibata, Y., Voeltz, G. K. and Rapoport, T. A. (2006) Rough sheets and smooth tubules. Cell. 126, 435-439

58 Voeltz, G. K. and Prinz, W. A. (2007) Sheets, ribbons and tubules - how organelles get their shape. Nat. Rev. Mol. Cell Biol. 8, 258-264

59 Zimmerberg, J. and Kozlov, M. M. (2006) How proteins produce cellular membrane curvature. Nat. Rev. Mol. Cell Biol. 7, 9-19

60 Hu, J., Shibata, Y., Voss, C., Shemesh, T., Li, Z., Coughlin, M., Kozlov, M. M., Rapoport, T. A. and Prinz, W. A. (2008) Membrane proteins of the endoplasmic reticulum induce high-curvature tubules. Science. 319, 1247-1250

61 Bernsel, A., Viklund, H., Falk, J., Lindahl, E., von Heijne, G. and Elofsson, A. (2008) Prediction of membrane-protein topology from first principles. Proc. Natl. Acad. Sci. U.S.A. 105, 7177-7181

62 Nziengui, H., Bouhidel, K., Pillon, D., Der, C., Marty, F. and Schoefs, B. (2007) Reticulon-like proteins in Arabidopsis thaliana: structural organization and ER localization. FEBS lett. 581, 3356-3362

63 Staehelin, L. A. (1997) The plant ER: a dynamic organelle composed of a large number of discrete functional domains. Plant J 11, 1151-1165

64 Murphy, D. J. and Vance, J. (1999) Mechanisms of lipid-body formation. Trends Biochem. Sci. 24, 109-115

65 Rahier, A., Darnet, S., Bouvier, F., Camara, B. and Bard, M. (2006) Molecular and enzymatic characterizations of novel bifunctional 3beta-hydroxysteroid dehydrogenases/C-4 decarboxylases from Arabidopsis thaliana. J. Biol. Chem. 281, 27264-27277

66 Schwacke, R., Schneider, A., van der Graaff, E., Fischer, K., Catoni, E., Desimone, M., Frommer, W. B., Flugge, U.-I. and Kunze, R. (2003) ARAMEMNON, a novel database for Arabidopsis integral membrane proteins. Plant Physiol. 131, 1626

67 Hwang, H.-H. and Gelvin, S. B. (2004) Plant proteins that interact with VirB2, the Agrobacterium tumefaciens pilin protein, mediate plant transformation. Plant Cell. 16, 3148-3167

68 Tolley, N., Sparkes, I. A., Hunter, P. R., Craddock, C. P., Nuttall, J., Roberts, L. M., Hawes, C., Pedrazzini, E. and Frigerio, L. (2008) Overexpression of a plant 
reticulon remodels the lumen of the cortical endoplasmic reticulum but does not perturb protein transport. Traffic. 9, 94-102

69 Dunkley, T. P., Hester, S., Shadforth, I. P., Runions, J., Weimar, T., Hanton, S. L., Griffin, J. L., Bessant, C., Brandizzi, F., Hawes, C., Watson, R. B., Dupree, P. and Lilley, K. S. (2006) Mapping the Arabidopsis organelle proteome. Proc. Natl. Acad. Sci. U. S. A. 103, 6518-6523

70 Contreras, I., Ortiz-Zapater, E. and Aniento, F. (2004) Sorting signals in the cytosolic tail of membrane proteins involved in the interaction with plant ARF1 and coatomer. Plant J. 38, 685-698

71 Nilsson, T., Jackson, M. and Peterson, P. A. (1989) Short cytoplasmic sequences serve as retention signals for transmembrane proteins in the endoplasmic reticulum. Cell. 58, 707-718

72 Shibata, Y., Voss, C., Rist, J. M., Hu, J., Rapoport, T. A., Prinz, W. A. and Voeltz, G. K. (2008) The reticulon and DP1/Yop1p proteins form immobile oligomers in the tubular endoplasmic reticulum. J Biol Chem. 283, 18892-18904

73 Heinlein, M., Padgett, H. S., Gens, J. S., Pickard, B. G., Casper, S. J., Epel, B. L. and Beachy, R. N. (1998) Changing patterns of localization of the tobacco mosaic virus movement protein and replicase to the endoplasmic reticulum and microtubules during infection. Plant Cell. 10, 1107-1120

74 Wright, K. M., Wood, N. T., Roberts, A. G., Chapman, S., Boevink, P., Mackenzie, K. M. and Oparka, K. J. (2007) Targeting of TMV movement protein to plasmodesmata requires the actin/ER network: evidence from FRAP. Traffic. 8, 21-31

75 Christensen, N. M., Faulkner, C. and Oparka, K. (2009) Evidence for unidirectional flow through plasmodesmata. Plant Physiol. 150, 96-104

76 Evans, D. E., Irons, S. L., Graumann, K. and Runions, J. (2009) The plant nuclear envelope. In Functional Organization of the Plant Nucleus. (Meier, I., ed.). pp. 9-28, Springer-Verlag Berlin, Heidelberg

77 Oparka, K. J. (2005) Plasmodesmata. Ann. Plant. Rev. 18 (Oparka, K, ed). pp 331 Blackwell, Oxford, UK

78 Hawes, C., Osterrieder, A., Hummel, E. and Sparkes, I. (2008) The plant ERGolgi interface. Traffic. 9, 1571-1580

79 Saint-Jore, C. M., Evins, J., Batoko, H., Brandizzi, F., Moore, I. and Hawes, C. (2002) Redistribution of membrane proteins between the Golgi apparatus and endoplasmic reticulum in plants is reversible and not dependent on cytoskeletal networks. Plant J. 29, 661-678.

80 Stefano, G., Renna, L., Chatre, L., Hanton, S. L., Moreau, P., Hawes, C. and Brandizzi, F. (2006) In tobacco leaf epidermal cells, the integrity of protein export from the endoplasmic reticulum and of ER export sites depends on active COPI machinery. Plant J. 46, 95-110

81 Robinson, D. G., Herranz, M.-C., Bubeck, J., Pepperkok, R. and Ritzenthaler, C. (2007) Membrane dynamics in the early secretory pathway. Crit. Rev. Plant Sci. 26, 199-225

82 Watson, P., Townley, A. K., Koka, P., Palmer, K. J. and Stephens, D. J. (2006) Sec16 defines endoplasmic reticulum exit sites and is required for secretory cargo export in mammalian cells. Traffic. 7, 1678-1687

83 Hanton, S. L., Chatre, L., Matheson, L. A., Rossi, M., Held, M. A. and Brandizzi, F. (2008) Plant Sar1 isoforms with near-identical protein sequences exhibit different localisations and effects on secretion. Plant Mol. Biol. 67, 283-294 
84 Chatre, L., Brandizzi, F., Hocquellet, A., Hawes, C. and Moreau, P. (2005) Sec22 and Memb11 are v-SNAREs of the anterograde endoplasmic reticulum-Golgi pathway in tobacco leaf epidermal cells. Plant Physiol. 139, 1244-1254

85 Yang, Y. D., Elamawi, R., Bubeck, J., Pepperkok, R., Ritzenthaler, C. and Robinson, D. G. (2005) Dynamics of COPII vesicles and the Golgi apparatus in cultured Nicotiana tabacum BY-2 cells provides evidence for transient association of Golgi stacks with endoplasmic reticulum exit sites. Plant Cell. 17, 1513-1531

86 Hanton, S. L., Chatre, L., Renna, L., Matheson, L. A. and Brandizzi, F. (2007) De novo formation of plant endoplasmic reticulum export sites is membrane cargo induced and signal mediated. Plant Physiol. 143, 1640-1650

87 Langhans, M., Hawes, C., Hillmer, S., Hummel, E. and Robinson, D. G. (2007) Golgi regeneration after brefeldin A treatment in BY-2 cells entails stack enlargement and cisternal growth followed by division. Plant Physiol. 145, 527-538

88 Robinson, D. G., Langhans, M., Saint-Jore-Dupas, C. and Hawes, C. (2008) BFA effects are tissue and not just plant specific. Trends Plant Sci. 13, 405-408

89 Hawes, C. and Satiat-Jeunemaitre, B. (2005) The plant Golgi apparatus--going with the flow. Biochim. Biophys. Acta. 1744, 466-480

90 Mollenhauer, H. H., Morre, D. J. and Vanderwoude, W. J. (1975) Endoplasmic reticulum-Golgi apparatus associations in maize root tips. Mikroskopie. 31, 257-272

91 Mollenhauer, H. H. and Morre, D. J. (1976) Transition elements between endoplasmic reticulum and Golgi apparatus in plant cells. Cytobiologie. 13, 297-306

92 Harris, N. and Oparka, K. J. (1983) Connections between dictyosomes, ER and GERL in cotyledons of mung bean (Vigna radiata L.). Protoplasma. 114, 93-102

93 Juniper, B., Hawes, C. R. and Horne, J. C. (1982) The relationship between dictyosomes and the forms of endoplasmic reticulum in plant cells with different export programs. Bot. Gaz. 143, 135-145

94 Kang, B. H. and Staehelin, L. A. (2008) ER-to-Golgi transport by COPII vesicles in Arabidopsis involves a ribosome-excluding scaffold that is transferred with the vesicles to the Golgi matrix. Protoplasma. 234, 51-64

95 Staehelin, L. A. and Kang, B. H. (2008) Nanoscale architecture of endoplasmic reticulum export sites and of Golgi membranes as determined by electron tomography. Plant Physiol. 147, 1454-1468

96 Barr, F. A. and Short, B. (2003) Golgins in the structure and dynamics of the Golgi apparatus. Curr. Opin. Cell Biol. 15, 405-413

97 Sztul, E. and Lupashin, V. (2006) Role of tethering factors in secretory membrane traffic. Am. J. Physiol. 290, C11-26

98 Latijnhouwers, M., Gillespie, T., Boevink, P., Kriechbaumer, V., Hawes, C. and Carvalho, C. M. (2007) Localization and domain characterization of Arabidopsis golgin candidates. J. Exp. Bot. 58, 4373-4386

99 Renna, L., Hanton, S. L., Stefano, G., Bortolotti, L., Misra, V. and Brandizzi, F. (2005) Identification and characterization of AtCASP, a plant transmembrane Golgi matrix protein. Plant Mol. Biol. 58, 109-122

100 Sinka, R., Gillingham, A. K., Kondylis, V. and Munro, S. (2008) Golgi coiledcoil proteins contain multiple binding sites for Rab family $G$ proteins. J. Cell Biol. 183, 607-615

101 Latijnhouwers, M., Hawes, C. and Carvalho, C. (2005) Holding it all together? Candidate proteins for the plant Golgi matrix. Curr. Opin. Plant Biol. 8, 632-639 
102 Osterrieder, A., Carvalho, C. M., Latijnhouwers, M., Johansen, J. N., Stubbs, C., Botchway, S. and Hawes, C. (2009) Fluorescence lifetime imaging of interactions between Golgi tethering factors and small GTPases in plants. Traffic. 10, 1034-1046 103 Stefano, G., Renna, L., Hanton, S. L., Chatre, L., Haas, T. A. and Brandizzi, F. (2006) ARL1 plays a role in the binding of the GRIP domain of a peripheral matrix protein to the Golgi apparatus in plant cells. Plant Mol. Biol. 61, 431-449

104 Hara-Nishimura, I., Shimada, T., Hatano, K., Takeuchi, Y. and Nishimura, M. (1998) Transport of storage proteins to protein storage vacuoles is mediated by large precursor-accumulating vesicles. Plant Cell. 10, 825-836

105 Toyooka, K., Okamoto, T. and Minamikawa, T. (2000) Mass transport of proform of a KDEL- tailed cysteine protease (SH - EP) to protein storage vacuoles by endoplasmic reticulum - derived vesicle is involved in protein mobilization in germinating seeds. J. Cell Biol. 148, 453-463

106 Petruccelli, S., Otegui, M. S., Lareu, F., Tran Dinh, O., Fitchette, A. C., Circosta, A., Rumbo, M., Bardor, M., Carcamo, R., Gomord, V. and Beachy, R. N. (2006) A KDEL-tagged monoclonal antibody is efficiently retained in the endoplasmic reticulum in leaves, but is both partially secreted and sorted to protein storage vacuoles in seeds. Plant Biotechnol. J. 4, 511-527

107 Frigerio, L., Pastres, A., Prada, A. and Vitale, A. (2001) Influence of KDEL on the fate of trimeric or assembly-defective phaseolin: selective use of an alternative route to vacuoles. Plant Cell. 13, 1109-1126

108 Huang, A. H. (1996) Oleosins and oil bodies in seeds and other organs. Plant Physiol. 110, 1055-1061

109 Shockey, J. M., Gidda, S. K., Chapital, D. C., Kuan, J. C., Dhanoa, P. K., Bland, J. M., Rothstein, S. J., Mullen, R. T. and Dyer, J. M. (2006) Tung tree DGAT1 and DGAT2 have non redundant functions in triacylglycerol biosynthesis and are localized to different subdomains of the endoplasmic reticulum. Plant Cell. 18, 22942313

110 Wahlroos, T., Soukka, J., Denesyuk, A., Wahlroos, R., Korpela, T. and Kilby, N. J. (2003) Oleosin expression and trafficking during oil body biogenesis in tobacco leaf cells. Genesis. 35, 125-132

111 Jolliffe, N. A., Craddock, C. P. and Frigerio, L. (2005) Pathways for protein transport to seed storage vacuoles. Biochem. Soc. Trans. 33, 1016-1018

112 Robinson, D. G., Oliviusson, P. and Hinz, G. (2005) Protein sorting to the storage vacuoles of plants: a critical appraisal. Traffic. 6, 615-625

113 Lending, C. R. and Larkins, B. A. (1989) Changes in the zein composition of protein bodies during maize endosperm development. Plant Cell. 1, 1011-1023

114 Hawes, C., Saint-Jore, C. M., Brandizzi, F., Zheng, H., Andreeva, A. V. and Boevink, P. (2001) Cytoplasmic illuminations: in planta targeting of fluorescent proteins to cellular organelles. Protoplasma. 215, 77-88

115 Matsushima, R., Kondo, M., Nishimura, M. and Hara-Nishimura, I. (2003) A novel ER-derived compartment, the ER body, selectively accumulates a betaglucosidase with an ER-retention signal in Arabidopsis. Plant J. 33, 493-502

116 Scott, I., Sparkes, I. A. and Logan, D. C. (2007) The missing link:interorganellar connections in mitochondria and peroxisomes? Trends Plant Sci. 12, 380381

117 Sinclair, A. M., Trobacher, C. P., Mathur, N., Greenwood, J. S. and Mathur, J. (2009) Peroxule extension over ER-defined paths constitutes a rapid subcellular response to hydroxyl stress. Plant J. 59, 231-242 
118 Novikoff, P. M. and Novikoff, A. B. (1972) Peroxisomes in absorptive cells of mammalian small intestine. J. Cell Biol. 53, 532-560

119 Lazarow, P. B. and Fujiki, Y. (1985) Biogenesis of peroxisomes. Annu. Rev. Cell Biol. 1, 489-530

120 Flynn, C. R., Heinze, M., Schumann, U., Gietl, C. and Trelease, R. N. (2005) Compartmentalization of the plant peroxin, AtPex10p, within subdomain(s) of ER. Plant Sci. 168, 635-652

121 Mullen, R. T., Lisenbee, C. S., Flynn, C. R. and Trelease, R. N. (2001) Stable and transient expression of chimeric peroxisomal membrane proteins induces an independent "zippering" of peroxisomes and an endoplasmic reticulum subdomain. Planta. 213, 849-863

122 Mullen, R. T., Lisenbee, C. S., Miernyk, J. A. and Trelease, R. N. (1999) Peroxisomal membrane ascorbate peroxidase is sorted to a membranous network that resembles a subdomain of the endoplasmic reticulum. Plant Cell. 11, 2167-2185

123 Lisenbee, C. S., Heinze, M. and Trelease, R. N. (2003) Peroxisomal ascorbate peroxidase resides within a subdomain of rough endoplasmic reticulum in wild-type Arabidopsis cells. Plant Physiol. 132, 870-882

124 Lisenbee, C. S., Karnik, S. K. and Trelease, R. N. (2003) Overexpression and mislocalization of a tail-anchored GFP redefines the identity of peroxisomal ER. Traffic. 4, 491-501

125 Karnik, S. K. and Trelease, R. N. (2005) Arabidopsis peroxin 16 coexists at steady state in peroxisomes and endoplasmic reticulum. Plant Physiol. 138, 19671981

126 Karnik, S. K. and Trelease, R. N. (2007) Arabidopsis peroxin16 trafficks through the ER and an intermediate compartment to pre-existing peroxisomes via overlapping molecular targeting signals. J. Exp. Bot. 58, 1677-1693

127 Sparkes, I. A., Hawes, C. and Baker, A. (2005) AtPEX2 and AtPEX10 are targeted to peroxisomes independently of known endoplasmic reticulum trafficking routes. Plant Physiol. 139, 690-700

128 McCartney, A. W., Greenwood, J. S., Fabian, M. R., White, K. A. and Mullen, R. T. (2005) Localisation of the tomato bushy stunt virus replication protein p33 reveals a peroxisome-to-endoplasmic reticulum sorting pathway. Plant Cell. 17, 35133531

129 Tabak, H. F., van der Zand, A. and Braakman, I. (2008) Peroxisomes: minted by the ER. Curr. Opin. Cell Biol. 20, 393-400

130 Titorenko, V. I. and Mullen, R. T. (2006) Peroxisome biogenesis : the peroxisomal endomembrane system and the role of the ER. J. Cell Biol. 174, 11-17

131 Kim, P. K., Mullen, R. T. and Lippincott-Schwartz, J. (2004) Evidence for endoplasmic reticulum origins of peroxisomes. Mol. Biol. Cell. 15, 621

132 Andersson, M. and Dormann, P. (2009) Chloroplast membrane lipid biosynthesis and transport. In The chloroplast. Interactions with the environment (Sandelius, A. and Aronsson, H., eds.), pp 125-128, Springer-Verlag, BerlinHeidelberg

133 McLean, B., Whatley, J. M. and Juniper, B. E. (1988) Continuity of chloroplasts and endoplasmic reticulum membranes in Chara and Equisetum. New Phytol. 109, 59-65

134 Xu, C., Fan, J., Cornish, A. J. and Benning, C. (2008) Lipid trafficking between the endoplasmic reticulum and the plastid in Arabidopsis requires the extraplastidic TGD4 protein. Plant Cell. 20, 2190-2204 
135 Andersson, M. X., Goksor, M. and Sandelius, A. S. (2007) Optical manipulation reveals strong attracting forces at membrane contact sites between endoplasmic reticulum and chloroplasts. J. Biol. Chem. 282, 1170-1174

136 Villarejo, A., Buren, S., Larsson, S., Dejardin, A., Monne, M., Rudhe, C., Karlsson, J., Jansson, S., Lerouge, P., Rolland, N., von Heijne, G., Grebe, M., Bako, L. and Samuelsson, G. (2005) Evidence for a protein transported through the secretory pathway en route to the higher plant chloroplast. Nat. Cell Biol. 7, 12241231

137 Nanjo, Y., Oka, H., Ikarashi, N., Kaneko, K., Kitajima, A., Mitsui, T., Munoz, F. J., Rodriguez-Lopez, M., Baroja-Fernandez, E. and Pozueta-Romero, J. (2006) Rice plastidial N-glycosylated nucleotide pyrophosphatase/phosphodiesterase is transported from the ER-golgi to the chloroplast through the secretory pathway. Plant Cell. 18, 2582-2592

138 Sievers, A. and Volkmann, D. (1972) Verursacht differentieller Druck der Amyloplasten auf ein komplexes Endomembranesystem die Geoperzeption in Wurzeln. Planta. 102, 160-172

139 Juniper, B. and French, A. (1973) The distribution and redistribution of endoplasmic reticulum (ER) in geoperceptive cells. Planta. 109, 211-224

140 Leitz, G., Kang, B. H., Schoenwaelder, M. E. and Staehelin, L. A. (2009) Statolith sedimentation kinetics and force transduction to the cortical endoplasmic reticulum in gravity-sensing Arabidopsis columella cells. Plant Cell. 21, 843-860 


\section{Figure legends}

Figure 1. Morphology and dynamics of higher plant ER.

Electron micrograph of an osmium impregnated maize root tip meristem cell (a) and confocal image of tobacco epidermal leaf cells expressing an ER lumenal marker (GFP-HDEL) (b) clearly showing the two structural domains, tubules and cisternal elements. Consecutive images were taken of GFP-HDEL in tobacco leaf epidermal cells, false coloured and overlaid to generate a single plane image. The dynamic nature of cortical ER remodelling is apparent as the 3 images were taken 6.5 seconds apart where white indicates GFP-HDEL fluorescence at all three time points (c). Scale bar 500nm (a) and $5 \mu \mathrm{m}(\mathrm{b}, \mathrm{c})$.

Figure 2. Schematic representation of higher plant ER dynamics.

ER tubule growth / retraction may be (in)dependent on Golgi body (G) movement; (1) Golgi body movement, via myosins (blue) processing along actin (blue arrowheads) remodels the attached / tethered ER (yellow spheres), or (2) Golgi body movement is a direct result of association with the ER. Actin polymerisation may also remodel the ER through interaction with actin associated factors (3, purple circles). Potential factors involved in three way junctions (red sphere) and anchor points (blue star) formation are unknown. ER tubulation appears to be due to reticulons (W), and their speculated hetero/homoligomerisation. Factors required for reticulon association / movement within the ER membrane are unknown (green circle).

\section{Figure 3. Evolutionary relationships of plant reticulon homology domains}

The RHD sequences from the indicated reticulon proteins were aligned with ClustalW. The tree was produced with MEGA4.1 using the minimum evolution method with 1000 bootstrap repetitions. Yeast Rtn1p and Rtn2p were used as the outgroup. Bootstrap test results are shown where higher than 50. P. patens, M. moellendorffii and $C$. reinhardtii reticulons are here defined as PpRTNLB, SmRTNLB and CrRTNLB, respectively. For their full accession numbers refer to supplementary figure S1.

Figure 4. Overexpression of AtRTNLB13 induces constrictions in the tubular ER.

Tobacco epidermal cells were agroinfiltrated with constructs encoding RTNLB13YFP (green) and the luminal ER marker RFP-HDEL (red). Note that while RTNLB13 labels the tubular ER, the luminal marker is constricted into discrete sections of the network. Scale bar, $5 \mu \mathrm{m}$.

Figure 5. Golgi micromanipulation affects ER remodelling.

A Golgi body (magenta, white arrow), in an Arabidopsis thaliana leaf epidermal cell treated with latrunculin $b$, was trapped and subsequent movement resulted in the remodelling of the associated ER (green). Sequential images from a movie sequence are shown and times are indicated. Scale bar $2 \mu \mathrm{m}$. 


\section{Supplementary material}

\section{Supplementary figure 1. Reticulon homology domains sequences used for}

phylogenetic analysis.

The sequences are shown in FASTA format. The accession numbers for each individual sequence are listed after the RTNLB numbers.

Supplementary movie 1. Movement of cortical ER in a tobacco leaf epidermal cell.

A time series of tobacco leaf epidermal cells expressing an ER marker, GFP-HDEL, was generated. Continual ER remodelling through tubule growth / retraction, three way junction formation, transitions between tubular and cisternal forms of ER, static regions or so called anchor points which the ER remodels around are observed. Some anchor points (blue circles) are highlighted, as is an area of cortical ER undergoing constant remodelling and transition from a tubular to cisternal form (white ellipse). Scale bar $5 \mu \mathrm{m}$.

Supplementary movie 2. Movement of cortical ER and Golgi bodies in an Arabidopsis epidermal leaf cell.

Golgi body (red) movement seemingly follows the cortical ER network (green). Scale bar $2 \mu \mathrm{m}$.

Supplementary movie 3. Movement of laser trapped Golgi bodies remodels the cortical ER.

The actin cytoskeleton in Arabidopsis leaf epidermal cells was depolymerised, and movement of trapped Golgi bodies (magenta) resulted in remodelling of the underlying ER network (green). Scale bar $5 \mu \mathrm{m}$. 
ER tubule growth / retraction
ER stability, 3

way junctons \& anchor points
ER tubulation versus cisternalisation
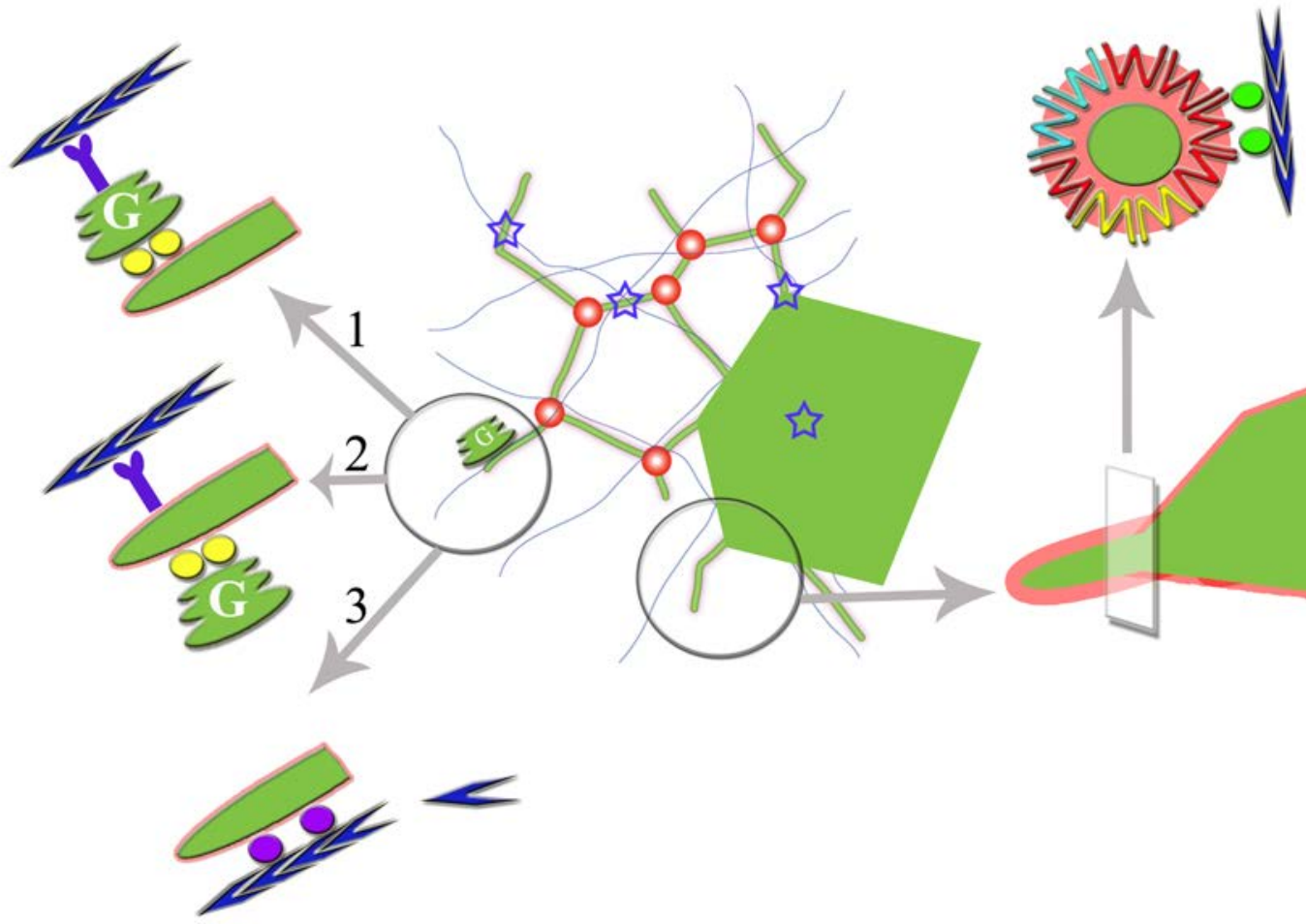
Arabidopsis thaliana

Selaginella moellendorffii

Physcomitrella patens

Chlamydomonas reinhardtii

Saccharomyces cerevisiae

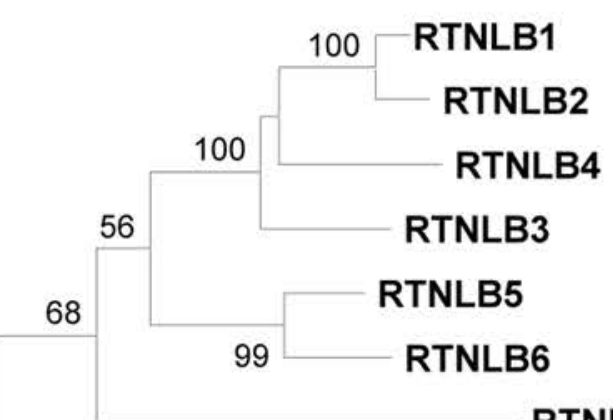

RTNLB7

RTNLB8

SmRTNLB1

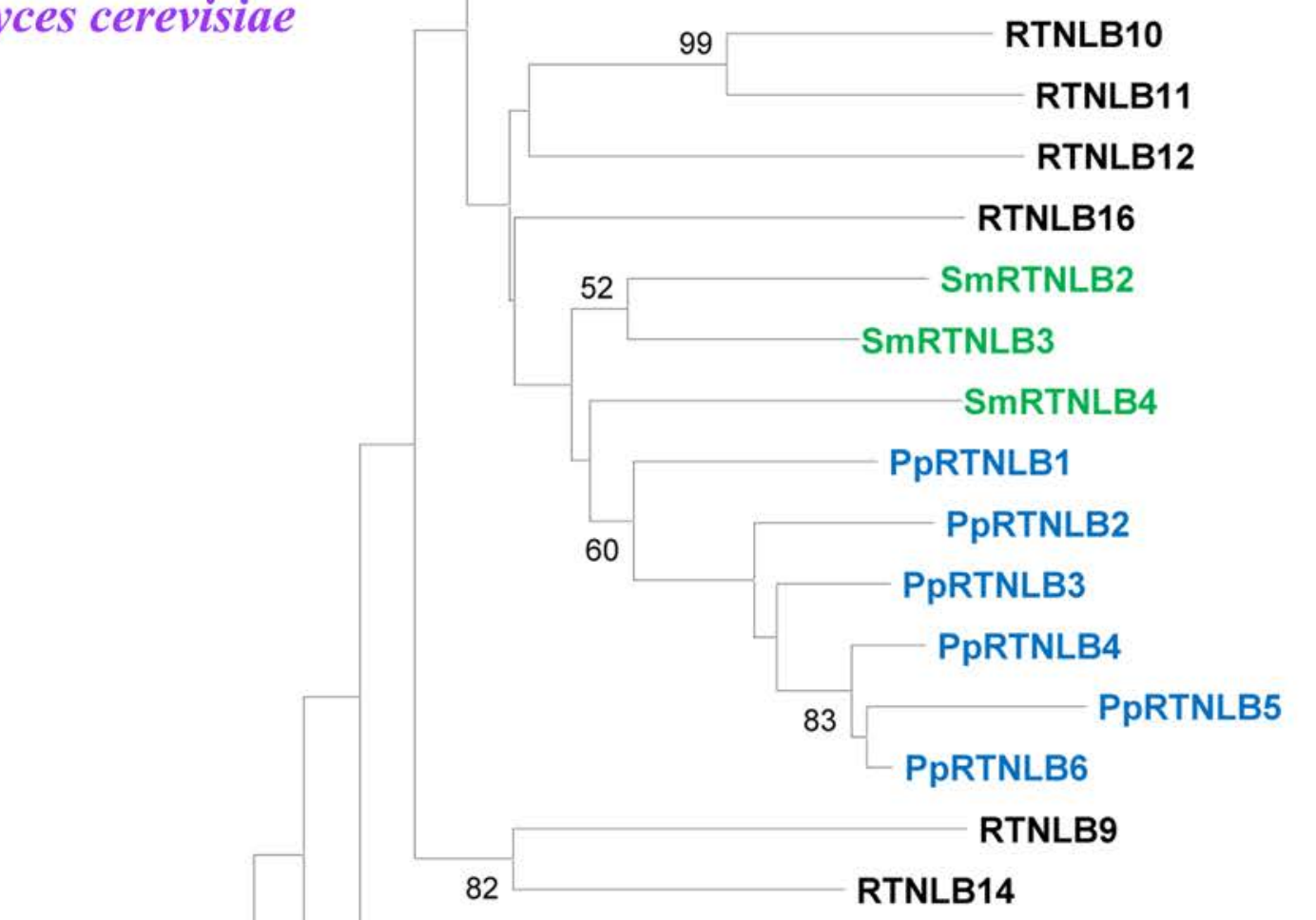

RTNLB15

RTNLB13

CrRTNLB1

66

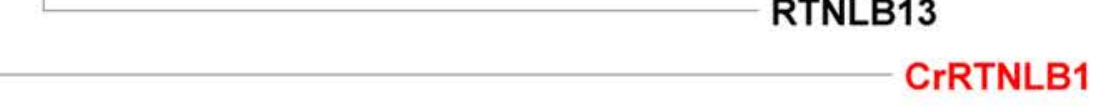

PpRTNLB7

88 RTNLB19

82

RTNLB20

RTNLB17

RTNLB18

RTNLB21

91

SmRTNLB5

PpRTNLB8

$98 \longrightarrow$ PpRTNLB9

100

Rtn1p

$\operatorname{Rtn} 2 p$

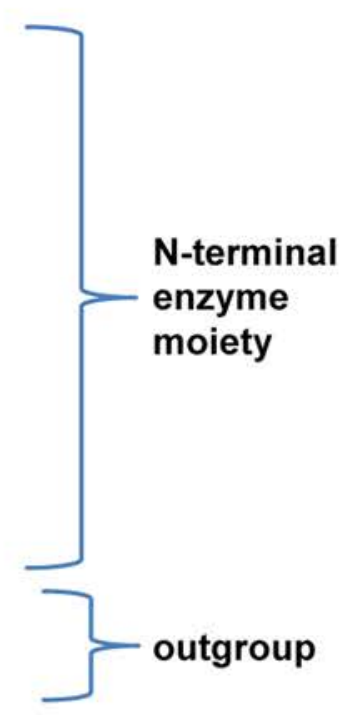



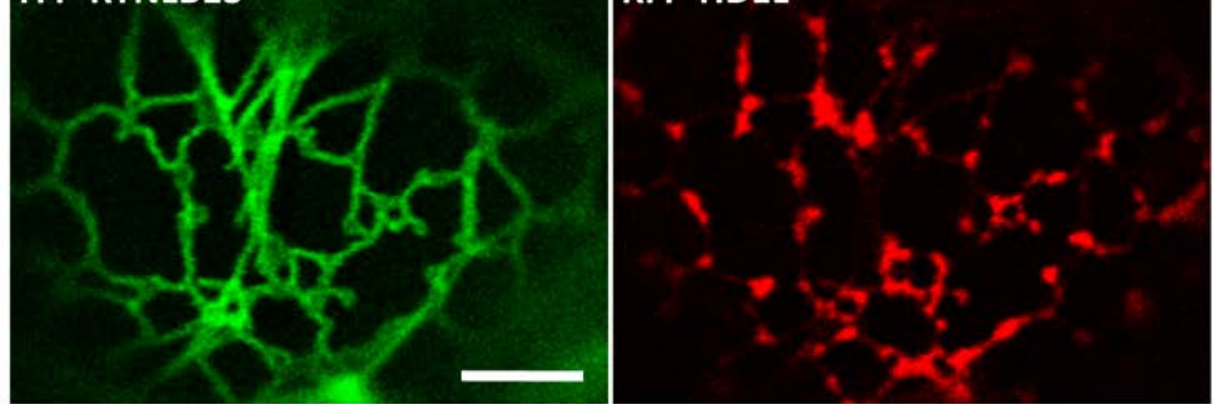

merge

Figure 4. Sparkes et al. 


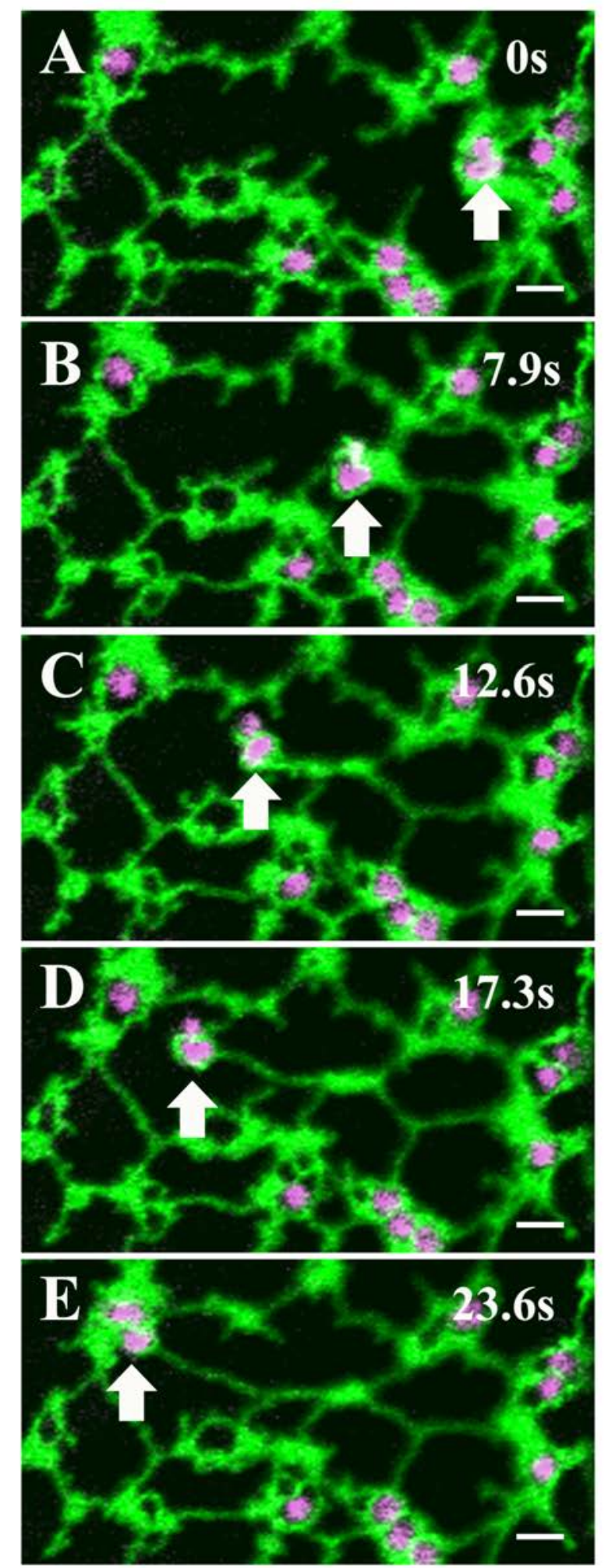

Figure 5. Sparkes et al. 
Supplementary figure 1. Sparkes et al.

Arabidopsis thaliana

\section{>AtRTNLB1 At4g23630}

GGVLGGATAAWVVFELMEYHLLTLLCHVMIVVLAVLFLWSNATMF INKS PPKI PEVH I PEEP ILQLASGLRIE INRGFSS LREIASGRDLKKFLIAIAGLWVLS ILGGCFNFLT LAYIAL

\section{>AtRTNLB2 At4g11220}

MSGGVFGGATVAWVLFELMEYHLLTLLCHVMIVALAVLFLWSNATMF I HKSPPKI PE VHI PEEPLLQLASGLRIEINRGISSLREIASGRDIKKFLSAIAGLWVLSILGGCYSF LTLAYIALVL

\section{>AtRTNLB3 At1g64090}

SGGVLGAATVSWILFELLEYNLLTLFGH IS I LALAVLFLWSSASTFIHKSPLHI PEV HIPEDVVLQLASGLRIEINRGFTVLRDIASGRDLKKFLLVIAGLWVLSKVGSSCNFL TLIYIA

\section{>AtRTNLB4 At5g41600}

VSGGVLGAVTASWVLFELFEYHLLAFLCHFAIFALAALFLWSNACTFIHKSTPHIPE VHI PEDP I LQLVSGLRIE INRGLTLLRNIASGKDVKKF I LVIAGLWVLS I IGSCYNF LTLFYTA

\section{>AtRTNLB5 At2g46170}

LSGAVLGVATAIWVLFELVEYHLLSLLCHIS I LALGGLFLWSNAHTLINKTSPQI PE IHVPEEAFLVVASSLRNELNQAFVILRS IALGRDLKKFLMVVVGLWI I SVVGNWFNF LTLVYI

\section{>AtRTNLB6 At3g61560}

LSASVLGVATAIWVLFELVEYHFLSLVCHILIFALAALFLLSNAHAFMNKTPPKIPE IHIKEEHFLMIVSALRNELNQAFVILRS IALGRDLKKF LMVVFGLWI ISVVGNWFNF LTLVYI

\section{>AtRTNLB7 At4g01230}

VTLGLLSAVTVIWLLFGFGGRRLLTSLCRGS I LFLLLSFLWSNALNKS PENMMDIY I PEKPLLQAASAMTFELNCAFATLRS IALERDIKNFVMAVIGLWLVSVIGNWFSFLSL LYIC

\section{>AtRTNLB8 At3g10260}

KISASVLMGATA IWVLFEWINFHFLSLVCYALLLGMIAQFVWSNASGFLNRSQSRVP RLVLPKDFFAEVGVAVGKEVNRGLLFLQDLACKGNLKQFLMAVIGLWVAAMVGSCCN FLTVLY

\section{>AtRTNLB9 At3g18260}

AATLVIGVS I LWF LMEVVEYNF ITLICHASMTSMLFFF IWSTASDFLNWERPLIPEV VLDESSFKQLARSFHVRFNQILTKLLDVACGRDP PLFFLTTISLYIVS I IGTYFNFV NLLFIG

\section{>AtRTNLB10 At2g15280}

GGFLLLGSTTLLWFLFEKCGYSFFPFVVNTQLLSVVILFLWAKSAILFNRPMPQLPN LEITEEFVFMVADAIRVWINTVLAVAREIYVGRNAKQLFRVSVVLWTVSFVGNFLNF LTILYLG

\section{>AtRTNLB11 At3g19460}

RTGAVILLISSTGFWFLFERAGYNLLSFVSNVLLLLVAIFFLWAKSATVLNRPLPPV PNME I PEEFANKAADDLRVWINYVLS IASDITIARNP IRLLQVSLVLWA I SYVGTLI NSLTLVYIG

>AtRTNLB12 At3g54120 
NVSVGIVTVTIASWMVFEAFAYTIFTLISSVLLLLLS ILFLWSKSAS ILNRPSPPLP EFQI SEAMAEEAS IWLRI HVNKLLQVSHDIAMARDSELYTKVAVSLFLLSLIGSLMD FQTLCHTS

\section{>AtRTNLB13 At2g23640}

KLAFSTLLVSTSTWILLSFYGFTTITIVSWIGIAVVSMIFLWGSLLRLLSKVEPELS GLEVSEEFVVETVRSCRMLMEEMVRWMFRVGAESEWFVFARTVLGFWILSRIGNLLD FHTCLFIG

\section{>AtRTNLB14 At1g68230}

KKESGTILGVFTLIWFLFEVVEYPFITFLCQILLLFIFIFLICKPPS INDLRISESN WRFLFNKINWF I IKLYDISSGKDFRLLFLAVVSLWILSVVGNYFSSLTLLYIGES

\section{>AtRTNLB15 At2g01240}

KLRDNTCNGHTLLVPLGVHGSS ISSASLLNLVTPHAHSLPLGQLNQP DSPLKALFSM MEGHLLMLYEIAYGKDNKTFLKTILYVAI IYNIGSYISLLTILYIC

\section{>AtRTNLB16 At3g10915}

HLSLGVIIISTVAWLIFEFSGLPFLSVSSDVLLIVIMISFVHARVSAFRNRQLHSLP ELVLSEEMVNSAAASFRIKLNHLLVMAHDVTVGNDFRLFFKVVICLWLLSAIGSYIS LCTLLYIG

\section{>AtRTNLB17 At2g20590}

KSTLWFGFGCLSFLSSCFAKGVNFSVFSAVSNLGLVLLCGSFLSNTLCQRKNEDTKR AFHVSEDDVLRSARRVLPATNFFISKTSELFSGEPSMTLKVTPFLLLGAEYGHLITL WRLSAFG

\section{>AtRTNLB18 At4g28430}

KSTLWFGFGCICFLSTCFAAKGFNFSVFSAISYLGLLFLGVSFLSNTLRQRVTEEAR RELKLSEDDVLRIARRMLPITNLAISKTSELFSGEPAMTLKVAPFVLMGAEYGYLIT LWRLCAFG

\section{>AtRTNLB19 At2g26260}

LKQTLIAIFILISIYYNFVATGSTVVTALSKALLVASVFLFLHGILPEKIFGYTVEK IPASQFHLSKDSSHDLSLSVISSWNTTVKALRSLCQGNDWSFFFKVVFVLLALSLAG AISLHSIFVIG

\section{>AtRTNLB20 At2g43420}

EKKTFVSFLVLNLFYYWFFFSGNTFTSSAAQLLFIFAVALYGVSFVPSKIFGFQVNK IPPWRFEISESAVRDLSSDIVVVWNQGVRSFKSLSSGGDWIKFFKIAGSLYLLKLIV SRSLAAFLFTV

\section{>AtRTNLB21 At5g58000}

RSTLVFGFGTFLI ISSSYANDLNFSF ISVVAYMGLIYLGLMFVLKSLIHRGMVEEER HKVVGVREEDVKRMLRLIMPYLNESLHQLRALFSGDPSTTLKMGVVLFVLARCGSS I TLWNLAKFG

Selaginella moellendorffii

>SmRTNLB1 gnl|Selmo1|271164 estext fgenesh1 kg.C 290002 KHLSASVLGIATLIYVLFEWCGYTVLSVFCNTFLLITIVLFVWSLGAS FTTRRPPPRI PELQLSEKTVQDVAHTVQLQFNNAVGAFRS IVLERNYVLFLKAAAGLWLLSTVGSWT SLLTLLYIGVIVAH

>SmRTNLB2 gnl|Selmo1|421735 fgenesh2_pg.C scaffold 53000092 GGILLGATVSYVLFEWCGYTLLS IASNALLFLVLILFTWSNLAALLDKPPPPIPEIQ LSEEMVENIAQTLRLELNRALGI I HMIALGKDFMLCVEVIAGLWIFSLVGGWCHFLT LLYFVVVLAH

>SmRTNLB3 gnl|Selmo1|179628 estext Genewise1Plus.C 540349 
TSLLVGSTVAWFLFEWSGYTLLSLVCNVLLFLIVILFLWATIASLLHRPPPPIPEIV LTEEMVHDSAATLRVEINKALLAAHDVAIGKDFRVFLKVTVVLWILSKLGAWFNFIT LVYILVVGAH

>SmRTNLB4 gnl|Selmo1|136377 e_gw1.147.83.1

IGILGGSTLVWFIFEWSGYTLISLVANIVLFLLIALFAWANLAALVNRPLPPVPEVQ LSDEKSNKIAKRVAKEVNGVLNYARSLSTGKDFPMLLKTCLMLWVLGNVGQWFSLLT LIYLGVIGTL

>SmRTNLB5 gnl|Selmo1|405772 fgenesh2_pg.C_scaffold_4000346 ALVMNVILWRDFSTSSLIFGAGAFAILSASLMQDIHLNIVTTLSYLALTYLSAVFFR INILRRAPSSSSDSWKISEAAALELTRGALPAFNAVLFKFSQLFSGDPGTTLKVAAT LCRMIPYAVAFFGAFLVPKFYVSYTA

Physcomitrella patens

>PPRTNLB1 PPP_5258_C1

CPGMNFNKAXRFSR̄NVALḠNDFKLFFKVVTLLWVVSTVASWFNLLTLIWIG

>PPRTNLB2 PPP_939_C1

PVELWAVRRSSGXLLLEKS GYTFLTLVCNILLFVVVILFVWSNVATLINRPGPPVPEL SLSENFVMNTANLIRIEVNKALHIARTVALGKDFKLFLLVVASLYVVS IVGSWFNLL TCVWIGI

>PPRTNLB3 PPP_2025_C1

KDRNLSAI ILGGST̄LVWF L̄LEKSGYTFLTLLSNI LMFSVI I LFVWANVAALLNRAGP PVPELSLSEDFVLRTASTVRVELNKALS IARDVALGKDFKLFLKMVVLLWVVSTVTS WENFLTCIWIG

>PPRTNLB4 PPP 4062_C1

KYLSAGTLGGSTLIIWFLVEKSGYTITTLICNILMLITVVLFVWSNVAALLKRPGPPV PELSLSEDFVLSTASVFRNEVNKALSAARTVALGKDFKLFFIVIAFLYVVSTVTSWF NFLTCIWIGI

>PPRTNLB5 PPP_939_C2

DKYLSGGTLFGSTĀIWYLLEKSGYTFVTLTCNILMCVIVLLFVWSS IAALLHRAGPP VPEL

>PPRTNLB6 PPP_4062_C2

LSAGTLGGSTLIWF̄LLEKSTGYTLVTLLCNILLFVIVILFLWSNVASLLHRPGPPFTV PELTLPEDLVLSTANVVRIEVNKALSVARTVALGKDFKLFFIVIAFLYVVSTVTSWF NFLTCIWIG

>PPRTNLB7 PPP_76_C1

KSAGLFFALFFFLY $S F \bar{Y} S$ SGTTLVSALTYNLCVALIAVFVYNLLPDPFFQISLPKIP SSSFEISEDGVKVVALQFDRIGIVSAXILERIVVQRDFSLFFKVMVLLRVVKFFGRF SFQSLLFMG

>PPRTNLB8 XM_001772054.1

SISANLALCYLA IVFFYRTFLSGSSAQSRSGQLKSSGVTEADFLGLIRFVLPTINLT LTKSGEVFSGDPAITLRVGSFILIKLYYWSLAVLADLYSF

>PPRTNLB9 XM_001764698.1

AISANLALCYLAVVVFFYRTFLHRSVAQSSGGQINSSEVTEADFLGLIQFVLPTINLA LNKSREIFSGDPATTLRVAIVLWLVSKMGAGVSIWSFLRFG

Chlamydomonas reinhardtii

>CrRTNLB1 XP_001698908 
KVRSTFYFVAGLLAWVVVRAVSKSDTTLFTGLCYVLLASLFWNFLRAAMAPAYAARC TWAHSAVTRFLVASATATLNAAAALHDRHLHGIDPLHTLEVGLGLWVLSLLGRALPF VTLLLLL

\section{Saccharomyces cerevisiae}

\section{>RTN1P YEAST}

PVQTGKYFGGSLLALLILKKVNLITFFLKVAYTILFTTGS IEFVSKLFLGQGLITKY GPKECPNIAGFIKPHIDEALKQLPVFQAHIRKTVFAQVPKHTFKTAVALFLLHKFFS WFS IWTIVFVA

\section{>RTN2P YEAST}

PSKSGASFAATLVSLLILRNVNVISVLLKIGYMVLFTSFAVELSTKVLFDKGVVSRE GMQESPDLVGVLKPHIDRELDRLPALEDRIRKLVFAHRTRNNFTIGVSLYFLHGLFA IFSMNTVLIMTT 